\title{
The Spectrin Skeleton: From Red Cells to Brain
}

Vann Bennett and Stephen Lambert

The Howard Hughes Medical Institute and the Department of Biochemistry,

Duke University Medical Center, Durham, North Carolina 27710

\section{Introduction}

A development from work with the plasma membrane of human erythrocytes over the past two decades has been discovery of the spectrin-based membrane skeleton, elucidation of its organization, and isolation and cloning of the major constituent proteins. The membrane skeleton of erythrocytes has already had implications for hematologists in that defects of proteins involved in the membrane skeleton have been found to result in hereditary hemolytic anemias. The spectrin skeleton also has a much broader relevance with components highly conserved from Drosophila to man that are expressed in many cell types. Physiological functions of spectrin skeletons in different cells are likely to be diverse but to involve the basic role of providing order for integral membrane proteins within the plane of the lipid bilayer and of coupling membrane proteins to components of the cytoskeleton. The focus of this review will be on the current status of nonerythroid spectrins and ankyrins, which are proteins that couple certain integral membrane proteins to spectrin. New developments with mutant mice will be described suggesting that the same genes for certain erythrocyte proteins are expressed in brain and can play a role in neurological disease.

\section{Overview of the Membrane Skeleton of Human Erythrocytes}

The spectrin skeleton can be viewed as a system of interacting proteins coordinated into an integrated structure. The skeleton thus is intermediate in complexity between a multisubunit enzyme and an organelle such as the endoplasmic reticulum. High resolution electron microscopy of the stretched membrane skeleton has provided striking images of a regular latticelike organization with five to six rod-shaped spectrin molecules attached to short actin filaments $30-50 \mathrm{~nm}$ in length to form a sheet of five and six sided polygons $(1,2)$ (Fig. 1).

Spectrin, the major structural component of this network, is a flexible rod-shaped molecule comprised of two subunits aligned side-to-side to form heterodimers and head-to-head into tetramers (Fig. 2). Spectrin requires additional proteins to form a membrane skeleton. Two classes of protein interactions have been identified as essential for assembly of spectrin tetramers into a membrane-associated network:

Linkage of spectrin to the membrane. Spectrin molecules

Received for publication 10 December 1990 and in revised form 3 February 1991.

J. Clin. Invest.

(c) The American Society for Clinical Investigation, Inc. 0021-9738/91/05/1483/07 \$2.00

Volume 87, May 1991, 1483-1489 have two distinct sites of interaction with integral membrane proteins that are likely to occur simultaneously. A major membrane attachment is provided by high-affinity association of the beta subunit of spectrin with ankyrin at a site located in the midregion of spectrin tetramers. Ankyrin is a peripheral membrane protein which, in turn, is associated with the cytoplasmic domain of the anion exchanger. Another association of spectrin with the membrane is mediated by protein 4.1 which is located at the ends of spectrin molecules and recognizes membrane sites that may include glycophorin $\mathrm{C}$ and the anion exchanger.

Association of multiple spectrin molecules with actin to form a two-dimensional meshwork. Spectrin molecules are cross-linked at their ends by association with actin. Several accessory proteins are found at these spectrin-actin junctions including protein 4.1 and protein 4.9. Other proteins are also candidates to participate in spectrin-actin interactions including adducin (3), tropomyosin (4), and a tropomyosin-binding protein named tropomodulin (5). Spectrin and the erythrocyte membrane have been the subject of several recent reviews (6-10).

Defects or deficiency in erythrocyte membrane skeletal proteins result in abnormally fragile red cells and mild to severe hereditary hemolytic anemias in humans and mice. These studies establish the principle that the membrane skeleton is essential for normal survival of erythrocytes in the circulation and that defects in structural proteins can be the basis for disease (reviewed in reference 11).

\section{The Spectrin Family}

Spectrin (also referred to as fodrin) includes a group of plasma membrane-associated proteins that are present in most vertebrate tissues (12) (Table I). Spectrins have also been characterized in nonvertebrates including Drosophila $(13,14)$ and echinoderms (15) and must have evolved before the divergence of arthropods. Spectrins have the following consensus properties: (a) Morphology of an extended, flexible molecule $\sim 200$ $260 \mathrm{~nm}$ in length comprised of two distinct extended rodshaped subunits of mol wt 225,000-430,000. The subunits, termed alpha and beta, are aligned laterally in an antiparallel arrangement to form heterodimers and head-head into tetramers $\sim 200 \mathrm{~nm}$ in length in the case of the most common form of spectrin. (b) Ability to associate with and cross-link actin filaments. (c) A calmodulin-binding site located in the midregion of the alpha subunit of most spectrins. Calmodulin-binding sites are missing, however, in the case of alpha spectrins of mammalian erythrocytes and Drosophila. (d) An ankyrinbinding site located on the beta subunit of most spectrins at a site in the midregion of the tetramer $(16,17)$.

Alpha and beta subunits of the spectrin family are homologous to each other and are primarily comprised of multiple 


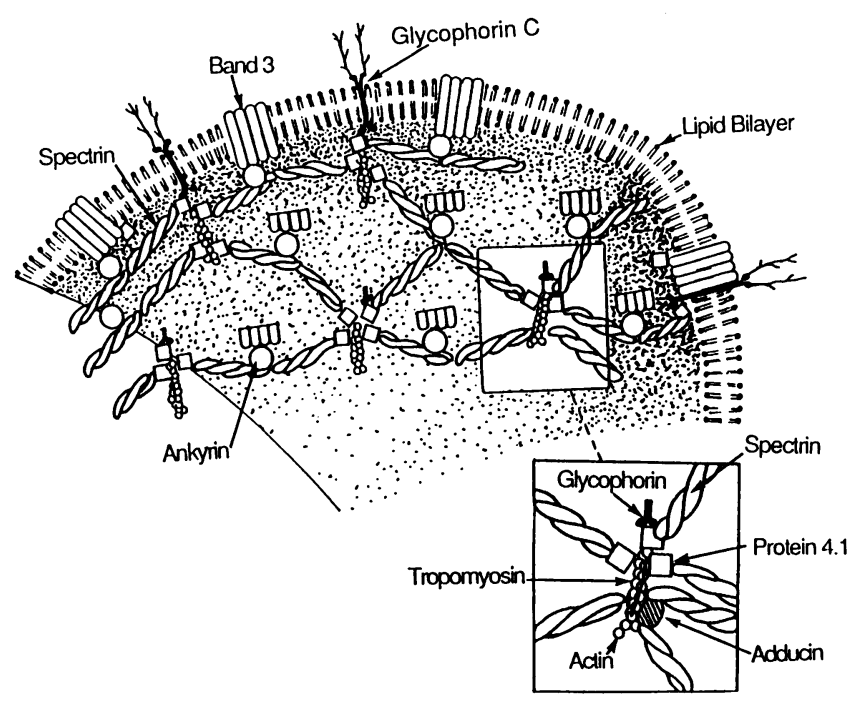

Figure 1. Schematic model of the organization of the spectrin skeleton of human erythrocytes.

versions of a 106-amino acid repeating sequence (18). Closely related versions of the 106-amino acid repeating sequence of spectrin subunits are present in proteins such as alpha-actinin (19) and dystrophin (20) suggesting that these proteins share a common evolutionary origin and form a newly defined superfamily of proteins. Structural models have been proposed for the folding of 106-residue repeats of spectrin into a series of short alpha-helical segments comprised of either three (18) or four (21) alpha helices. The proposed series of alpha-helical units is consistent with the amount of alpha helix predicted from circular dichroism spectra, and would account for the reduced length and increased flexibility of spectrin compared with other coiled-coil alpha-helical proteins.

Mammals express two types of alpha subunit which are products of distinct genes: a tissue-invariant alpha subunit located on human chromosome 9 which is expressed in all mammalian tissues except for mature erythrocytes (22), and the erythrocyte alpha subunit located on human chromosome 1 (23). Birds and presumably other animals have a single alpha subunit expressed in erythrocytes as well as other tissues.

The beta subunits of spectrin contain most of the recognition sites of spectrin for other proteins including ankyrin (17, 24 ), protein $4.1(25)$, actin (26), as well as the site for ankyrinindependent association of spectrin with membranes (27). The beta subunits also are the major source of diversity among spectrins, with a growing list of variants with specialized functions. The beta subunit family currently includes five isoforms that are likely to be encoded by distinct genes: $(a)$ Beta $_{\mathrm{G}}$, a generally distributed tissue invariant polypeptide that binds preferentially to brain ankyrin as opposed to erythrocyte ankyrin. (b) Beta $_{\mathrm{R}}$, first characterized in erythrocytes that also is expressed as alternatively spliced forms in brain and skeletal muscle (28). Beta $\mathrm{R}_{\mathrm{R}}$ associates preferentially with erythrocyte ankyrin compared to brain ankyrin. (c) Beta $\mathrm{Tw}_{\mathrm{Tw}}$, a specialized subunit associated with terminal web in the apical domain of intestinal epithelial cells and which is found in birds but not in

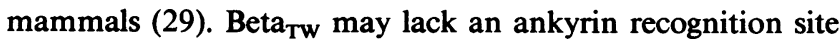
based on in vitro assays (8). (d) Beta $_{\mathrm{NM}}$, a beta-type subunit identified at neuromuscular junctions based on cross-reactivity with antibodies (30). The beta-related subunit at neuromuscular junctions may be an exception to the general rule that beta subunits are associated with alpha subunits, because no alpha subunit could be detected by antibodies (30). (e) Beta $\mathrm{B}_{\mathrm{H}}$, a 430,000-D polypeptide initially discovered in Drosophila (31) that forms tetramers with the alpha subunit that are $260 \mathrm{~nm}$ in length.

Several examples have been noted where two beta subunits are expressed in same cell but are localized in specialized domains. Avian intestinal epithelial cells have beta ${ }_{\text {Tw }}$ in their api-

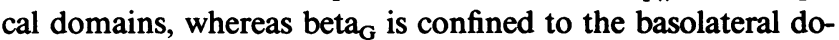
mains (29). Purkinje cells in the cerebellum that have beta $a_{R}$ in their cell bodies and beta $\mathrm{G}_{\mathrm{G}}$ in axons $(32,33)$. Expression of a specialized beta subunit is turned on during differentiation of myoblasts (34), and is likely to be subject to interesting tissuespecific and developmental controls.

The complete sequence has been determined of cDNAs encoding the alpha subunits of spectrin from chicken brain (35), human erythrocytes (36), Drosophila (14), and human lung (37). The alpha subunits of tissue spectrins have a very high degree of conservation of at least $90 \%$ identity between vertebrate species and 63\% identity between Drosophila and chicken. The human erythrocyte alpha subunit, in contrast, has $\sim 50-60 \%$ identity with the general human alpha subunit, and currently represents the most divergent member of the alpha spectrin family.

The midregion of all spectrin alpha subunits includes a sequence that has homology with the $\mathrm{SH} 3$ portion of the regulatory domains of several src-tyrosine kinases and a domain of the gamma isoform of phospholipase $C$ (35). Other proteins that have a similar motif include a yeast actin-binding protein and myosin 1 of Dyctiostelium (38). All of the proteins identified so far with a SH3 motif have the feature of association with the membrane cytoskeleton (38). Intriguing possibilities suggested by the sequence homology between spectrin and other structural proteins with the regulatory domains of tyrosine kinases are that these enzymes are regulated by interactions with structural proteins or that the $\mathrm{SH} 3$ motif is responsible for targeting a variety of proteins to the vicinity of the plasma membrane through association with a common class of molecules.

Sequence information for the beta spectrins includes the complete sequence of human erythrocyte beta $a_{R}(28)$, and par-

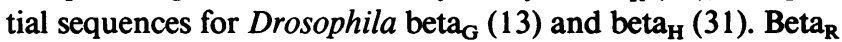
contains three distinct regions: an $\mathrm{NH}_{2}$-terminal domain (residues 1-272) that is a candidate to contain the actin-binding site (26), a domain comprising the major portion of beta spectrin composed of 17 consecutive 106 residue repeats, and a $\mathrm{COOH}$ terminal domain of 52 residues that is responsible for headhead association within the $\mathrm{NH}_{2}$-terminus of the alpha subunit. The ankyrin-binding site is likely to be located in repeat 15 , which has a stretch of sequence that diverges from the

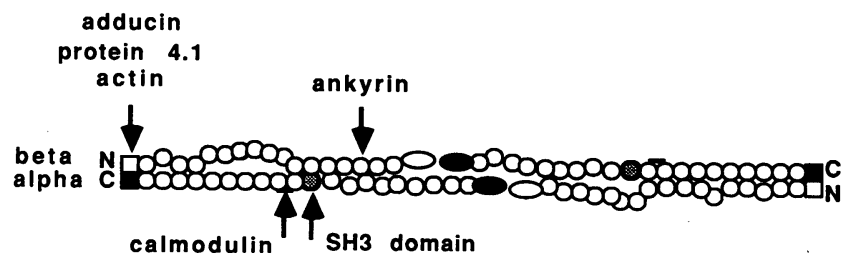

Figure 2. Schematic model of spectrin structure 0 symbols represent 106 residue repeats. 
Table I. The Spectrin Family

\begin{tabular}{lll}
\hline Subunits* $^{*}$ & \multicolumn{1}{c}{ Proteins } & \multicolumn{1}{c}{ Tissue } \\
\hline Alpha $_{\mathrm{g}}$ & Alpha $_{\mathrm{g}}$, beta $_{\mathrm{g}}$ & Generally distributed \\
Alpha $_{\mathrm{rbc}}$ & Alpha $_{\mathrm{rbc}}$, beta $_{\mathrm{r}}^{\ddagger}$ & Erythrocytes \\
Beta $_{\mathrm{g}}$ & Alpha $_{\mathrm{g}}$, beta $_{\mathrm{r}}$ & Brain, muscle \\
Beta $_{\mathrm{r}}$ & Alpha $_{\mathrm{g}}$, beta $_{\mathrm{tw}}$ & Avian intestine \\
Beta $_{\mathrm{r}}$ & Alpha?, beta $_{\mathrm{nm}}$ & Neuromuscular junction \\
Beta $_{\text {tw }}$ & & \\
Beta $_{\text {nm }}$ & & \\
Beta $_{\mathrm{h}}{ }^{8}$ & & \\
\hline
\end{tabular}

* Arbitrary nomenclature for the purpose of this review.

${ }^{\ddagger}$ Encoded by the same gene as beta, but alternatively spliced with an extension at the $\mathrm{COOH}$-terminal end (28).

${ }^{8}$ Recently discovered in Drosophila (31); localization in vertebrates not known.

106-residue repeat motif (28). Drosophila beta spectrins both have high homology within the $\mathrm{NH}_{2}$-terminal actin-binding domain, with $77 \%$ sequence identity (13). The actin-binding domain of beta spectrin also is conserved between members of the spectrin/alpha actinin/dystrophin gene family as well as other actin-binding proteins that associate laterally with actin filaments including Dictyostelium gelation-factor (39) and nonmuscle filamin (40).

\section{Ankyrins}

Ankyrins, like spectrins, are a family of proteins that are associated with the plasma membranes of many types of cells. Ankyrins have properties that suggest a role as adaptors between certain integral membrane proteins and the spectrin skeleton. Erythrocyte ankyrin, the first member of this family to be characterized, provides a high-affinity linkage between spectrin and the cytoplasmic domain of the anion exchanger (41). Ankyrin is a large protein of $206-\mathrm{kD}$ that contains three independentlyfolded domains: (a) an $\mathrm{NH}_{2}$-terminal 89-kD domain that binds to the anion exchanger (42); (b) a 62-kD domain (apparent mol wt 72,000 on SDS gels) that binds to spectrin (43); and (c) a $\mathrm{COOH}$-terminal $55-\mathrm{kD}$ regulatory region comprised of at least two domains that modulates activity of the binding domains (44) (Fig. 3). The complete sequence of human erythrocyte ankyrin has been deduced from analysis of cDNA which encodes a protein of 1,881 amino acids from a mRNA of $7 \mathrm{~kb}$ $(45,46)$.

A striking feature of the $89-\mathrm{kD}$ domain of ankyrin is the presence of 22 repeats containing 33-residues that occur in tandem. The repeats contain 15 highly conserved and 18 variable residues. Related 33-residue motifs are present in a number of apparently unrelated proteins of broad phylogenetic distribution (see 45 for references): (a) cytoplasmic domains of membrane proteins involved in cell differentiation including Lin 12 and Glp-1 of C. elegans, Notch protein of Drosophila and Xotch of Xenopus (47); (b) cytosolic proteins involved in cellcycle regulation such as SW16 and SW14 of S. cerevisiae and $\mathrm{CDC} 10$ of $S$. pombe where the 33-residue motif was first noted (48); (c) the precursor to Nf-kappa B, a ubiquitous transcription factor $(49,50)$. The functional basis for these homologous sequences is not clear, although a shared interaction with a common class of molecules is a reasonable guess.

The $89-\mathrm{kD}$ domain is globular and has a $\mathrm{CD}$ spectrum con- sistent with $30 \%$ alpha helix (42). These physical properties provide some boundary conditions for predictions of the organization and folding of the 33-amino acid repeating sequences. The value of $30 \%$ alpha helix implies a single helix of 10 residues per repeat if it is assumed that each repeat is folded in a quasiequivalent manner. The globular shape of the $89-\mathrm{kD}$ domain suggests that the repeats fold into a sphere and not into an extended rod as is the case of many proteins with multiple repeated sequences. It is of interest that another form of ankyrin from brain also has 22 repeats of 33 amino acids (Otto, E., M. Kunimoto, and V. Bennett, manuscript in preparation). The maximum number of ankyrin repeats thus may be 22 if the repeats are packed into a sphere.

Immunoreactive forms of ankyrin have been detected associated with the membranes of a number of tissues in addition to erythrocytes by radioimmunoassay, immunoblots of SDS gels, and immunofluorescence $(41,51)$. An isoform of ankyrin has been purified from brain which has properties in common with erythrocyte ankyrin, although it is the product of a distinct gene (17) (see below). Brain and erythrocyte ankyrin share physical properties (asymmetric monomers of mol wt $\sim 200,000$ ), have a similar domain structure, associate with the beta subunit of spectrin at a site close to the midregion of spectrin tetramers, and both proteins bind to the cytoplasmic domain of the erythrocyte anion exchanger. The two ankyrins also share the property of binding to tubulin via the $89-\mathrm{kD}$ domain.

Recent work indicates that erythrocyte and brain ankyrins are prototypes of two families of ankyrin that have major differences in cellular expression and localization $(52,53)$. Anky$\operatorname{rin}_{R}$ forms or restricted ankyrins react better with antibodies against RBC ankyrin, are expressed in a limited number of cells in brain and kidney, and have a highly polarized distribution within these cells. Ankyrin ${ }_{R}$ in the nervous system is expressed primarily in neurons, and in kidney is present in high concentrations in distal tubule cells and intercalated cells of the collecting duct $(52,54)$. Ankyrin $_{R}$ forms are localized at specialized cell domains such as the node of Ranvier (53), postsynaptic membrane of the neuromuscular junction (55), and basolateral surfaces of epithelial cells $(51,54)$. Ankyrin ${ }_{R}$ also is
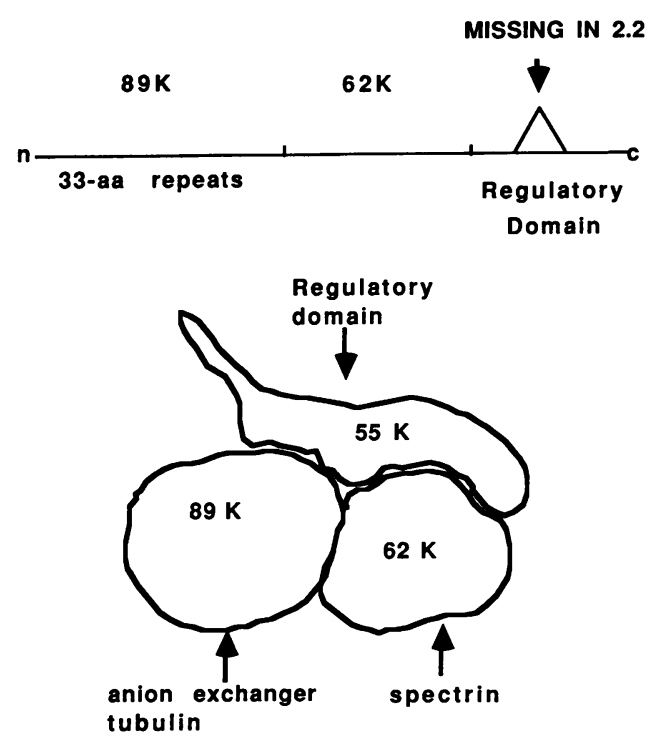

Figure 3. Schematic model of ankyrin. 
present in nerve cell bodies, at the initial segment of axons, dendrites, and in unmyelinated axons (53).

Several ion channels colocalize with ankyrin $_{R}$ in specialized membrane domains and interact with erythrocyte ankyrin in in vitro assays: the anion exchanger of kidney collecting ducts (56), the alpha 1 isoform of the $\mathrm{Na} / \mathrm{K}$ ATPase of kidney $(54,57$, 58 ), and the voltage-dependent sodium channel of brain (59). A current working hypothesis is that ankyrin plays a role in either initial targeting of these ion channels to specialized areas of the cell or in maintaining them once the membrane domains have assembled.

Members of the ankyrin ${ }_{B}$ group cross-react better with antibodies against the major form of ankyrin in brain, and are expressed in most cells of brain and kidney. Ankyrin $n_{B}$ is present in kidney in glomeruli, proximal and distal tubules, and loops of Henle (52). Ankyrin ${ }_{B}$ in brain is present in glial as well as neuronal cells, and does not exhibit a high concentration at the nodes of Ranvier. Neither form of ankyrin is present in internodal regions of myelinated axons, at least as detected with available antibodies, even though these areas of the membrane contain spectrin. One candidate for a membrane attachment site for ankyrin $_{B}$ forms include a broadly distributed membrane glycoprotein, termed Pgp-1, gp-85, or CD44 antigen (60), which is likely to participate in intercellular adhesion. Another ankyrin-binding protein termed AGP-200 has been detected in brain (61). Recent experiments in our laboratory using ankyrin ${ }_{\mathrm{B}}$-affinity columns suggest that multiple membrane proteins recognize this form of ankyrin (62).

Differences in cellular localization of ankyrins may be due to variations in relative affinities for target proteins. Functional differences between the ankyrin $_{R}$ and ankyrin ${ }_{B}$ isoforms have been demonstrated using in vitro assays employing erythrocyte and brain ankyrin as prototypes of these families. Each type of ankyrin binds preferentially to a distinct type of spectrin: brain ankyrin better with the general form of spectrin and erythrocyte ankyrin better with erythrocyte spectrin $(17,63)$. The specificity of ankyrins for spectrin isoforms is likely to be important in differential targeting of ankyrins at least in brain where both erythroid and general spectrin are coexpressed in the same cells but localized in different domains of certain neurons $(32,33)$. Membrane binding sites for ankyrins also are distinct in brain and kidney (52). The specificity of membrane sites for ankyrins in kidney was not absolute, but reflected differences in relative affinities. Further evidence for common features in binding sites was that the cytoplasmic domain of the erythrocyte anion exchanger displaced membrane binding of both ankyrins.

cDNA encoding ankyrin ${ }_{B}$ from human brain has recently been cloned and sequenced (Otto, E., M. Kunimoto, and V. Bennett, manuscript in preparation). Brain ankyrin is encoded by a gene located on chromosome 4 (Otto et al., manuscript in preparation), whereas the gene for erythrocyte ankyrin is located on chromosome 8 (46). The open reading frame of brain ankyrin cDNA encodes a protein of $202 \mathrm{kD}$, which is close to the size of erythrocyte ankyrin. Two major regions of high homology to erythrocyte ankyrin are present in the sequence of brain ankyrin: one involves the 33-residue repeats which are present in 22 tandem copies in both proteins, and the other area of homology is located within the spectrin-binding domains. Conservation within the repeat domains of these ankyrins includes preservation of the number of repeats, and the feature that the fourth repeat in both proteins is the only repeat to deviate from the 33-residue periodicity. Moreover, each re- peat in brain ankyrin is more closely related to the corresponding repeat in erythrocyte ankyrin, strongly suggesting that these sequences arose by duplication of an ancestoral gene that also contained 22 copies of this motif.

Two areas of almost complete divergence between the two ankyrins are at the connection between the 33-residue repeat domain and the spectrin-binding domain, and in the regulatory domains. These areas of sequence differences are candidate sites to explain the functional differences between brain and $\mathrm{RBC}$ ankyrins.

How many different genes encode ankyrins? The information to answer this question still is incomplete, although a minimum number may be five distinct ankyrin genes. Northern blots and immunoblots with antibody raised against recombinant proteins indicate that the two ankyrins from kidney are distinct from both brain and RBC ankyrin, and that liver has a unique form of ankyrin not present in brain, RBCs, or kidney (Otto et al., manuscript in preparation). Moreover, in brain tissue, ankyrin ${ }_{R}$ at the node of Ranvier may be encoded by a different gene than ankyrin ${ }_{R}$ in neuronal cell bodies because

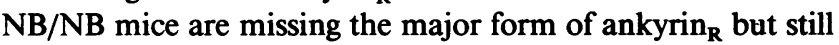
express an ankyrin at their nodes of Ranvier (64).

A rational nomenclature to describe these different ankyrins has not been formulated, and probably will require additional information. Simply using the tissue origin to designate ankyrins is not sufficient. For example, the same gene that encodes erythrocyte ankyrin also is responsible for a form of ankyrin in the cerebellum and forebrain $(64,65)$.

\section{Functional Diversity of Ankyrin Due to Alternative Splicing} of $m R N A$

Erythrocyte ankyrin has a regulatory region comprising several domains which are located at the carboxy terminal end of the polypeptide. One of these domains, located near the carboxy terminus, is cleaved by calpain and results in an ankyrin with reduced binding to the anion exchanger in erythrocyte membranes (44). Another regulatory domain is located $\mathrm{NH}_{2}$-terminal to the calpain-sensitive domain. Deletion of this domain results in a lower molecular weight form of ankyrin present in human erythrocyte membranes known as protein 2.2. Protein 2.2 results from differential processing of mRNA, because the missing region, as identified by antibodies, lies internally within the sequence (45). Moreover, cDNA clones have been isolated that contain an in-frame deletion of 163 amino acids that include the portion of sequence missing in protein 2.2 $(45,46)$.

The alternatively spliced protein 2.2 is an activated ankyrin with an increased affinity for spectrin and increased association with the anion exchanger in erythrocyte membranes (44). Protein 2.2 also expresses a binding site for a major class of unidentified protein sites in kidney microsomes that do not recognize the larger form of ankyrin (52). The regulatory region thus defines specificity in binding to membrane sites as well as modulates affinities. The explanation for increased activities of protein 2.2 is not known. One possibility is a conformational difference between 2.2 and intact ankyrin. Another alternative is that the domain missing in 2.2 occupies binding sites as a pseudosubstrate, as occurs with regulatory domains of several protein kinases.

The phenomenon of alternative splicing of ankyrin mRNA is likely to involve regions in addition to the region missing in protein 2.2 and to be a feature of other members of the ankyrin 
family. In the case of erythrocyte ankyrin, a highly basic stretch of 32 residues ( $\mathrm{pl}>10$ ) located at the $\mathrm{COOH}$-terminus of the regulatory domain is also alternatively spliced (46). Another candidate site that would have a significant functional consequence would be in the region interconnecting the $89-\mathrm{kD}$ and spectrin-binding domains. A potential example of splicing in brain involves ankyrin ${ }_{B}$ which exhibits two sizes of mRNA on Northern blots that encodes two ankyrins with quite different regulatory domains (Otto et al., manuscript in preparation).

\section{Mapping the Binding Sites of Ankyrin}

How does ankyrin interact selectively with the anion exchanger, $\mathrm{Na} / \mathrm{K}$ ATPase, and voltage-sensitive sodium channel as well as other membrane proteins that remain to be identified? The available evidence, based on examination of the binding sites of ankyrin for the anion exchanger and $\mathrm{Na} / \mathrm{K}$ ATPase supports the view that ankyrin-binding activity evolved independently at least in the case of these proteins (42). The anion exchanger binds exclusively to the 89-kD domain (see below), whereas the $\mathrm{Na} / \mathrm{K}$ ATPase binds only weakly to the $89-\mathrm{kD}$ domain and also associates with the spectrin-binding domain (66). The $\mathrm{Na} / \mathrm{K}$ ATPase thus may require contacts with two and perhaps more domains of ankyrin to form the high-affinity complex observed with intact ankyrin.

The anion exchanger-binding site of ankyrin is completely contained within the 89-kD domain of human erythrocyte ankyrin and is retained by proteolytic fragments containing only 33-residue repeats (42). The 33-residue repeats thus play a major role in association of ankyrin with the anion exchanger. The issue of whether the repeats are equivalent with respect to binding to the anion exchanger has been explored using defined regions of human erythrocyte and brain ankyrins expressed in bacteria (67). The conclusion was that the repeats are not interchangeable and that the 44 residues from 722 to 765 are essential for high-affinity binding between erythrocyte ankyrin and the anion exchanger.

The finding that specificity in association between ankyrin and the anion exchanger is provided by a rather small region of sequence raises the question of what is the function(s) of the remaining 20 33-residue repeats of the $89-\mathrm{kD}$ domain. One possibility is that the other 33 -amino acid repeats interact with proteins distinct from the anion exchanger. The ability to interact with multiple proteins is not required in the context of the anucleate mammalian erythrocyte. However, the same gene encoding erythrocyte ankyrin also is expressed in brain (64, 65). The complex environment of the nervous system could provide a variety of potential ankyrin-binding proteins.

\section{Spectrin and Ankyrin in Specialized Membrane Domains}

Isoforms of both ankyrin and spectrin are segregated to specialized regions of cell membranes, and may play a role in either establishing or maintaining local concentrations of integral membrane proteins. Ankyrin associates and is colocalized with several polarized membrane proteins, including the anion exchanger in basolateral domains of kidney collecting ducts (56), the voltage-dependent $\mathrm{Na}$ channel at nodes of Ranvier of nerve (54) and the neuromuscular junction (55) and the $\mathrm{Na} / \mathrm{K} \mathrm{ATP}$ ase of basolateral domains of kidney distal tubule cells $(54,57$, 58). Examples of highly polarized distributions of spectrin are the concentration of spectrin at the node of Ranvier (68), and in caps of lymphocytes in tissues (69). Spectrin also is a signifi- cant component of postsynaptic densities of brain (70). A variant of the beta subunit of spectrin is associated with the postsynaptic membrane of the neuromuscular junction and is colocalized with acetylcholine receptors (30).

These observations establish that spectrin, either directly or through ankyrin, has the potential for localization in specialized regions of cell membranes. An important issue is whether spectrin and ankyrin play a role in establishing membrane domains. A range of possibilities include participation in initial targeting of membrane proteins, stabilization of membrane domains after they have formed, or having a role in both maintenance and initial assembly of membrane domains. A complex containing the $\mathrm{Na} / \mathrm{K}$ ATPase, ankyrin, and spectrin has been isolated from cultured epithelial cells that is detergent soluble and may represent a precursor to the mature, detergent insoluble assembly of these proteins on the plasma membrane (71). Ankyrin and the $\mathrm{Na} / \mathrm{K}$ ATPase thus are likely to associate before the $\mathrm{Na} / \mathrm{K}$ ATPase reaches the plasma membrane, although it is not known whether these proteins interact in the Golgi or endoplasmic reticulum. How the ankyrin/ATPase complex is targeted to basolateral membranes remains an open question. It seems likely that information from the external side of the plasma membrane will be involved in the targeting event.

\section{Clinical Implications}

The phenotype of anemia has established the importance of spectrin and its associated proteins in normal function of erythrocytes. In view of the widespread nature of these structural systems, it is likely that the spectrin skeleton may be involved in a spectrum of cell membrane-related diseases in other tissues. Given the diverse nature of these structural proteins, arising from both multiple genes and alternative mRNA splicing, a large number of tissue-specific defects could be foreseen that would be compatible with survival.

A good starting point in the search for such diseases would be proteins such as beta ${ }_{R}$ spectrin and ankyrin $_{R}$ which are encoded by the same genes in erythrocytes, skeletal muscle, and some neurons in the central nervous system. The NB/NB strain of mice, for example, lack erythrocyte ankyrin and also are deficient in this form of ankyrin in the cerebellum, where it is almost completely missing from the cell bodies of Purkinje and granule cells $(64,65)$. Other ankyrin genes still are expressed including ankyrin at the node of Ranvier and the major form of brain ankyrin. These animals develop a tremor and other signs of cerebellar dysfunction (65). Moreover, the Purkinje cells gradually die until at age 6-9 mo the number is reduced by $50 \%(65)$. A defect in a specific ankyrin gene thus can lead to neuronal degeneration in these mice and potentially in humans as well. It is of interest that neurological symptoms have been reported associated with hereditary spherocytosis (72-75), although these cases may be relatively rare. In view of the potential for multiple ankyrin-binding proteins within a neuron, it is likely that defects in ankyrin can occur which do not alter the activity in erythrocytes but will affect neuronal function.

A prediction from the NB/NB mouse model is that defects in some members of ankyrin or spectrin families will result in degenerative diseases of long-lived cells such as neurons and muscle cells. These proteins have multiple isoforms that may be able to compensate in the short term, but may not be able to prevent cell damage over the course of years. Such degenerative 
diseases may be currently viewed as a normal consequence of aging.

\section{Acknowledgments}

Ms. Brenda Sampson is gratefully acknowledged for help in preparing the manuscript.

Research from our laboratory was supported in part by grants from the National Institutes of Health.

\section{References}

1. Byers, T. J., and D. Branton. 1985. Visualization of the protein associations in the erythrocyte membrane skeleton. Proc. Natl. Acad. Sci. USA. 82:61536157.

2. Liu, S. C., L. H. Derick, and J. Palek. 1987. Visualization of the hexagonal lattice in the erythrocyte membrane skeleton. J. Cell Biol. 104:527-536.

3. Gardner, K., and V. Bennett. 1987. Modulation of spectrin-actin assembly by erythrocyte adducin. Nature (Lond.). 328:359-362.

4. Fowler, V., and V. Bennett. 1984. Erythrocyte membrane tropomyosin: purification and properties. J. Biol. Chem. 259:5978-5989.

5. Fowler, V. 1990. Tropomodulin: a cytoskeletal protein that binds to the end of erythrocyte tropomyosin and inhibits tropomyosin binding to actin. J. Cell Biol. 111:471-482.

6. Bennett, V. 1989. The spectrin-actin junction of erythrocyte membrane skeleton. Biochim. Biophys. Acta. 988:107-121.

7. Bennett, V. 1990 . The spectrin-based membrane skeleton: a multipotential adaptor between plasma membrane and cytoplasm. Physiol. Rev. 70:1029-1065.

8. Coleman, T. R., D. J. Fishkind, M. S. Mooseker, and J. S. Morrow. 1989. Functional diversity among spectrin isoforms. Cell Motil. Cytoskeleton 12:225247.

9. Mangeat, P. H. 1988. Interaction of biological membranes with the cytoskeleton framework of living cells. Biol. Cell. 64:261-281.

10. Goodman, S. R., K. E. Krebs, C. F. Whitfield, B. M. Riederer, and I. S. Zagon. 1988. Spectrin and related molecules. CRC Crit. Rev. Biochem. 23:171234.

11. Palek, J., and S. Lambert. 1990. Genetics of the red cell membrane skeleton. Semin. Hematol. 27:290-332.

12. Repasky, E., B. Granger, and E. Lazarides. 1982. Widespread occurrence of avian spectrin in nonerythroid cells. Cell. 29:321-833.

13. Byers, T., A. Husain-Chishti, R. Dubreuil, D. Branton, and L. Goldstein 1989. Sequence similarity of the amino-terminal domain of Drosophila beta spectrin to alpha actinin and dystrophin. J. Cell Biol. 109:1633-1641.

14. Dubreuil, R., T. Byers, A. Sillman, D. Bar-Zvi, L. Goldstein, and D. Branton. 1989. The complete sequence of Drosophila alpha-spectrin: conservation of structural domains between alpha-spectrins and alpha-actinin. J. Cell Biol. 109:2197-2205.

15. Fishkind, D. J., M. S. Mooseker, and E. M. Bonder. 1985. Actin assembly and filament cross-linking in the presence of TW 260/240, the tissue-specific spectrin of the chicken intestinal brush border. Cell Motil. 5:311-322.

16. Tyler, J. M., W. R. Hargreaves, and D. Branton. 1979. Purification of two spectrin-binding proteins: biochemical and electron microscopic evidence for site-specific reassociation between spectrin and bands 2.1 and 4.1. Proc. Natl. Acad. Sci. USA. 76:5192-5196.

17. Davis, J., and V. Bennett. 1984. Brain ankyrin: a membrane associated protein with binding sites for spectrin, tubulin and the cytoplasmic domain of the erythrocyte anion channel. J. Biol. Chem. 259:13550-13559.

18. Speicher, D. W., and V. T. Marchesi. 1984. Erythrocyte spectrin is composed of many homologous triple helical segments. Nature (Lond.). 31 1:177-180.

19. Baron, M. D. M. D. Davison, P. Jones, and D. R. Critchley, 1987. The sequence of chick alpha-actinin reveals homologies to spectrin and calmodulin. $J$. Biol. Chem. 262:17623-17629.

20. Koenig, M., A. P. Monaco, and L. M. Kunkel. 1988. The complete sequence of dystrophin predicts a rod-shaped cytoskeletal protein. Cell. 53:219228.

21. Davison, M., M. Baron, J. Wooten, and D. Critchley. 1989. Structural analysis of homologous repeated domains in alpha-actinin and spectrin. Int. J. Biol. Macromol. 11:81-90.

22. Leto, T. L., D. Fortugno-Erikson, D. Barton, T. L. Yang-Feng, U. Francke, A. S. Harris, J. S. Morrow, V. T. Marchesi, and E. J. Benz, Jr. 1988. Comparison of nonerythroid alpha-spectrin genes reveals strict homology among diverse species. Mol. Cell. Biol. 8:1-9.

23. Huebner, K., A. P. Palumbo, M. Isobe, C. A. Kozak, S. Monaco, G. Rovera, C. M. Croce, and P. J. Curtis. 1985. The alpha-spectrin gene is on chromosome 1 in mouse and man. Proc. Natl. Acad. Sci. USA. 82:3790-3793.

24. Calvert, R., P. Bennett, and W. Gratzer. 1980. Properties and structural role of the subunits of human spectrin. Eur. J. Biochem. 107:355-361.
25. Coleman, T. R., A. S. Harris, S. M. Mische, M. S. Mooseker, and J. S. Morrow. 1987. Beta spectrin bestows protein 4.1 sensitivity on spectrin-actin interactions. J. Cell Biol. 104:519-526.

26. Karinch, A., W. Zimmer, and S. Goodman. 1990. The identification and sequence of the actin-binding domain of human red cell $\beta$-spectrin. J. Biol. Chem. 265:11833-11840.

27. Steiner, J., and V. Bennett. 1988. Ankyrin-independent membrane protein binding sites for brain and erythrocyte spectrin. J. Biol. Chem. 263:1441714425.

28. Winkelmann, J., F. Costa, B. Linzie, and B. Forget. 1990. Beta spectrin in human skeletal muscle: tissue-specific differential processing of 3 'beta spectrin pre-mRNA generates a beta spectrin isoform with a unique carboxy-terminus. $J$. Biol. Chem. 265:20449-20454.

29. Glenney, J., P. Glenney, and K. Weber. 1983. The spectrin related molecule TW $260 / 240$ cross-links actin bundles of the microvillus rootlets in the brush borders of intestinal epithelial cells. J. Cell Biol. 96:1491-1496.

30. Bloch, R. J., and J. S. Morrow. 1989. An unusual beta-spectrin associated with clustered acetylcholine receptors. J. Cell Biol. 108:481-493.

31. Dubreuil, R., T. Byers, C. Stewart, and D. Kiehart. 1990. A beta-spectrin isoform from Drosophila is similar in size to vertebrate dystrophin. J. Cell Biol. 111:1849-1858.

32. Lazarides, E., and W. Nelson. 1983. Erythrocyte and brain forms of spectrin in cerebellum: distinct membrane-cytoskeletal domains in neurons. Science (Wash. DC). 220:1295-1296.

33. Riederer, B. M., I. S. Zagon, and S. R. Goodman. 1986. Brain spectrin $(240 / 235)$ and brain spectrin (240/235E): two distinct spectrin subtypes with different locations within mammalian neural cells. J. Cell Biol. 102:2088-2097.

34. Nelson, W. J., and E. Lazarides. 1983. Switching of subunit composition of muscle spectrin during myogenesis in vitro. Nature (Lond.). 304:364-368.

35. Wasenius, V. W., M. Saraste, P. Salven, M. Eramaa, L. Holm, and V. P. Lehto. 1989. Primary structure of the brain alpha-spectrin. J. Cell Biol. 108:7993.

36. Sahr, K , P Laurila, L Kotula, A Scarpa, E Coupal, T Leto, A. Linnenbach, J. Winkelmann, D. Speicher, V. Marchesi, P. Curtis, and B. Forget. 1990. The complete cDNA and polypeptide sequences of human erythroid alpha-spectrin. J. Biol. Chem. 265:4435-4443.

37. Moon, R., and A. McMahon. 1990. Generation of diversity of nonerythroid spectrins. J. Biol. Chem. 265:4427-4433.

38. Drubin, D., J. Mulholland, Z. Zhu, and D. Botstein. 1990. Homology of a yeast actin-binding protein to signal transduction proteins and myosin-1. Nature (Lond.). 343:288-290.

39. Noegel, A., S. Rapp, F. Lottspeich, M. Schleicher, and M. Stewart. 1989. The Dictyostelium gelation-factor shares a putative actin-binding site with alphaactinins and dystrophin and also has a rod domain containing six 100 residue motifs that appear to have a cross-beta conformation. J. Cell Biol. 109:607-618.

40. Gorlin, J. B., R. Yamin, S. Egan, M. Stewart, T. P. Stossel, D. J. Kwiatkowski, and J. H. Hartwig. 1990. Human endothelial actin-binding protein (ABP-280, nonmuscle filamin): a molecular leaf spring. J. Cell Biol. 111:10891106.

41. Bennett, V. 1985. The membrane skeleton of human erythrocytes and its implications for more complex cells. Annu. Rev. Biochem. 54:273-304.

42. Davis, L., and V. Bennett. 1990. Mapping the binding sites of human erythrocyte ankyrin for the anion exchanger and spectrin. J. Biol. Chem. 265:10589-10596.

43. Bennett, V. 1978. Purification of an active proteolytic fragment of the membrane attachment site for human erythrocyte spectrin. J. Biol. Chem. 253:2292-2299.

44. Hall, T. G., and V. Bennett. 1987. Regulatory domains of erythrocyte ankyrin. J. Biol. Chem. 262:10537-10545.

45. Lux, S. E., K. John, and V. Bennett. 1990. Analysis of cDNA for human erythrocyte ankyrin indicates a repeated structure with homology to tissue-differentiation and cell-cycle control proteins. Nature (Lond.). 344:36-42.

46. Lambert, S., H. Yu., J. Prchal, J. Lawler, P. Ruff, D. Speicher, M. Cheung Y. Kan, and J. Palek. 1990. cDNA sequence for human erythrocyte ankyrin. Proc. Natl. Acad. Sci. USA. 87:1730-1734.

47. Coffman, C., W. Harris, and C. Kintner. 1990. Xotch, the Xenopus homo$\log$ of Drosophila notch. Science (Wash. DC). 249:1438-1441.

48. Breeden, L., and K. Nasmyth. 1987. Similarity between cell-cycle genes of budding yeast and the Notch gene of Drosophila. Nature (Lond.). 329:651-654.

49. Ghosh, S., A. Gifford, L. Riviere, P. Tempst, G. Nolan, and D. Baltimore. 1990. Cloning of the p50 DNA subunit of NF-KB: homology to rel and dorsal. Cell. 62:1019-1029.

50. Kieram, M., V. Blank, F. Logeat, J. Vandekerckhove, F. Lottspeich, O. LeBail, M. Urban, P. Kourilisky, P. Baeverle, and A. Israel. 1990. The DNAbinding subunit of NF-KB is identical to factor KBF1 and homologous to the rel oncogene product. Cell. 62:1007-1018.

51. Drenckhahn, D., and V. Bennett. 1987. Polarized distribution of $M_{\text {r }}$ 210,000 and 190,000 analogs of erythrocyte ankyrin along the plasma membrane of transporting epithelia, neurons and photoreceptors. Eur. J. Cell Biol. 43:479486. 
52. Davis, J., L. Davis, and V. Bennett. 1989. Diversity in membrane binding sites of ankyrins: brain ankyrin, erythrocyte ankyrin, and processed erythrocyte ankyrin associate with distinct sites in kidney microsomes. J. Biol. Chem. 264:6417-6426.

53. Kordeli, E., J. Davis, B. Trapp, and V. Bennett. 1990. An isoform of ankyrin is localized at nodes of Ranvier in myelinated axons of central and peripheral nerves. J. Cell Biol. 110:1341-1352.

54. Koob, R., M. Zimmermann, W. Schoner, and D. Drenckhahn. 1988. Colocalization and coprecipitation of ankyrin and $\mathrm{Na} / \mathrm{K}$ ATPase in kidney epithelial cells. Eur. J. Cell Biol. 45:230-237.

55. Flucher, B., and M. Daniels. 1989. Distribution of $\mathrm{Na}^{+}$channels and ankyrin in neuromuscular junctions is complementary to that of acetylcholine receptors and the $43 \mathrm{kd}$ protein. Neuron. 3:163-175.

56. Drenckhahn, D., K. Schluter, D. Allen, and V. Bennett. 1985. Colocalization of band 3 with ankyrin and spectrin at the basal membrane of intercalated cells in the rat kidney. Science (Wash. DC). 230:1287-1289.

57. Nelson, W. J., and P. J. Veshnock. 1987. Ankyrin binding to the $\mathrm{Na}^{+}$ $+\mathrm{K}^{+}$) ATPase and implications for the organization of membrane domains in polarized cells. Nature (Lond.). 328:533-535.

58. Morrow, J. S., C. D. Cianci, T. Ardito, A. S. Mann, and M. Kashgarian. 1989. Ankyrin links fodrin to the alpha subunit of Na K-ATPase in Madin-Darby canine kidney cells and in intact renal tubule cells. J. Cell Biol. 108:455-465.

59. Srinivasan, Y., L. Elmer, J. Davis, V. Bennett, and K. Angelides. 1988. Ankyrin and spectrin associate with voltage-dependent sodium channels in brain. Nature (Lond.). 333:177-180.

60. Kalomiris, E. L., and L. Y. Bourguignon. 1988. Mouse T lymphoma cells contain a transmembrane glycoprotein (GP85) that binds ankyrin. J. Cell Biol. 106:319-327.

61. Treharne, K. J., D. Rayner, and A. J. Baines. 1988. Identification and partial purification of ABGP205, an integral membrane glycoprotein from brain that binds ankyrin. Biochem. J. 253:345-350.

62. Davis, J., E. Otto, and V. Bennett. 1990. Ankyrin binding proteins in brain. J. Cell Biol. 3:46a. (Abstr.)

63. Bennett, V., J. Davis, and W. Fowler. 1982. Brain spectrin, a membraneassociated protein related in structure and function to erythrocyte spectrin. $\mathrm{Na}$ ture (Lond.). 299:126-131.

64. Kordeli, E., L. Peters, J. Barker, and V. Bennett. 1990. Distinct genes encode erythroid ankyrin ( ankyrin $_{R}$ ) at neuron cell bodies and nodes of Ranvier. J. Cell Biol. 111:46a. (Abstr.)
65. Peters, L. L., C. S. Birkenmeier, R. Bronson, R. A. White, S. E. Lux, and J. E. Barker. 1990. The hemolytic anemia mutation, $n b$, includes a neurological component resulting from a deficiency of erythroid ankyrin in the purkinje cells of the cerebellum. Blood. 76:14a. (Abstr.)

66. Davis, J. Q., and V. Bennett. 1990. The anion exchanger and $\mathrm{Na}+\mathrm{K}+$-ATPase interact with distinct sites on ankyrin in in vitro assays. $J$. Biol. Chem. 265:17252-17256.

67. Davis, L., E. Otto, and V. Bennett. 1990. The anion exchanger recognizes specific CDC10/Notch 33-residue repeat(s) of erythrocyte ankyrin. J. Cell Biol. 111:45a. (Abstr.)

68. Koenig, E., and E. Repasky. 1985. A regional analysis of alpha-spectrin in the isolated Mauthner neuron and in isolated axons of the goldfish and rabbit. $J$. Neurosci. 5:704-714.

69. Repasky, E. A., D. E. Symer, and R. B. Bankert. 1984. Spectrin immunofluorescence distinguishes a population of naturally capped lymphocytes in sites. J. Cell Biol. 99:350-355.

70. Carlin, R. C., D. C. Bartelt, and P. Siekevitz. 1983. Identification of fodrin as a major calmodulin-binding protein in postsynaptic density preparations. $J$. Cell Biol. 96:443-448.

71. Nelson, W. J., and R. W. Hammerton. 1989. A membrane-cytoskeletal complex containing $\mathrm{Na}+, \mathrm{K}+-\mathrm{ATPase}$. Ankyrin and fodrin in Madin-Darby canine kidney (MDCK) cells: implications for the biogenesis of epithelial cell polarity. J. Cell Biol. 108:893-902.

72. Coetzer, T. L., J. Lawler, S. C. Liu, J. T. Prchal, R. J. Gaultieri, M. C. Mrain, J. V. Dacie, and J. Palek. 1988. Partial ankyrin and spectrin deficiency in severe, atypical hereditary spherocytosis. N. Engl. J. Med. 318:230-234.

73. Lux, S. E., W. T. Tse, J. C. Menninger, K. M. John, P. Harris, O. Shalev, R. R. Chilcote, S. L. Marchesi, P. C. Watkins, V. Bennett, S. McIntosh, F. S. Collins, U. Francke, D. C. Ward, and B. G. Forget. 1990. Hereditary spherocytosis associated with deletion of human erythrocyte ankyrin gene on chromosome 8. Nature (Lond.). 345:736-739.

74. McCann, S. R., and H. S. Jacobs. 1976. Spinal cord disease in hereditary spherocytosis: support of two cases with a hypothesized common mechanism for neurologic and red cell abnormalities. Science (Wash. DC). 48:259-263.

75. Kitatani, M., H. Chiyo, M. Ozaki, S. Shike, and S. Miwa. 1988. Localization of the spherocytosis gene to chromosome segment 8 p11.22 8p21.1. Hum. Genet. 78:94-95. 